Available online on 15.06 .2020 at http://jddtonline.info
Open Access to Pharmaceutical and Medical Research
(c) 2011-18, publisher and licensee JDDT, This is an Open Access article which permits
unrestricted non-commercial use, provided the original work is properly cited

Open@Access

Research Article

\title{
Pharmacognostic Screening of Elaeis guineensis ( Aracaceae) Jacq. Oil and its Effect as an Antidote on Cyanide Poisoning
}

\author{
*Osuala Felix N. ${ }^{1}$, Odoh Uchenna E. ${ }^{2}$, Muoneme Grace 0.1 ${ }^{1}$, Ohadoma Sylvester C. ${ }^{3}$ \\ ${ }^{1}$ Department of Pharmacognosy, Madonna University Nigeria, Elele Campus, Rivers State, Nigeria \\ 2 Department of Pharmacognosy and Environmental Medicine, Univerity of Nigeria, Nsukka, Nigeria \\ ${ }^{3}$ Department of Pharmacology, College of Medical Sciences, University of Calabar, Nigeria
}

\begin{abstract}
Introduction: Elaeis guinenesis is a perennial monocot belonging to the family Arecaceae. It is the source of the oil commonly called African palm oil or macaw fat which in traditional medicine has many uses

Aim: This study is focused on the pharmacognostic screening of oil of Elaeis guineensis, and its antidotal effect on cyanide poisoning.

Method: The extracted oil was subjected to various screening technique in order to determine its quality, purity and chemical constituents. The oil was macroscopically examined; acute toxicity test of Elaeis guineensis oil was carried out on rats. The oil was subjected to heating to determine the moisture content. Phytochemical analysis was also carried out on the palm oil extract. The physicochemical analysis was carried to determine the acid value, saponification value, ester value, hydroxyl value and iodine value. The Ld 50 for the pure cyanide was carried out on the rats using "Up and Down" method. The antidotal study of Elaeis guineensis oil was carried out on the rats.

Result: Macroscopic evaluation showed, the oil was in fresh condition, smooth texture, bright red colour, characteristic taste, oily appearance and a characterictic smell. The Phytochemical analysis showed the presence of flavonoids, phenols, tannins, saponnins, alkaloids, steroids and terpenoids. The physicochemical analysis showed that the oil has an acid value of 31.2, Saponification value of 194.8, Ester value 163.54 Peroxide value of 18.0, Hydroxyl Percentage of $2.07 \%$ and Free Fatty Acid of 3.65. The moisture content was calculated to be $0.2 \%$. For the acute toxicity test on the oil using Lorkes method no death was recorded. The $\mathrm{LD}_{50}$ of the cyanide carried out on the rats showed that the lethal dose of cyanide is $5 \mathrm{mg} / \mathrm{kg}$. The antidotal effect of Elaeis guineensis oil showed the absence of death on the group given oil extract alone and the groups that were poisoned and given the oil (antidote) within 4 minutes. Deaths were recorded for the groups that were admini stered antidotes after 8 minutes.
\end{abstract}

Conclusion: Elaeis guineensis oil has counteracting effect on cyanide poisoning if administered within four minutes of cyanide ingestion.

Keywords: Elaeis guineensis, phytochemical analysis, physicochemical analysis, macroscopy antidotal effect.

Article Info: Received 21 March 2020; Review Completed 28 April 2020; Accepted 11 May 2020; Available online 15 June 2020

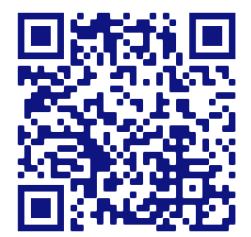

Cite this article as:

Osuala FN, Odoh UE, Muoneme GO, Ohadoma SC, Pharmacognostic Screening of Elaeis guineensis (Aracaceae) Jacq. Oil and its Effect as an Antidote on Cyanide Poisoning, Journal of Drug Delivery and Therapeutics. 2020; 10(3-s):1-5 http://dx.doi.org/10.22270/jddt.v10i3-s.4054

Osuala Felix N., Department of Pharmacognosy, Madonna University Nigeria, Elele Campus, Rivers State, Nigeria

\section{INTRODUCTION}

It is hard to find any indigenous food prepared in Nigeria without the use of palm oil and this explains the vital role it plays in daily diets. Currently, palm oil is the world largest edible oil and is the main source of domestic or edible oil in Africa ${ }^{1}$. Fresh palm oil is the most common Antidote for ingested poisons amongst indigenous people of south-south Nigeria. In traditional medicine, palm oil is a very popular antidote.
Poison can be defined as a substance that can cause animals to die or become very sick when taken in a very small quantity into their bodies. ${ }^{2}$

Antidotes are substances when taken that can stop the harmful effect of a poison or correct and improve the bad effects $^{2}$

In Medieval Europe, there was increased availability of poisons; shops known as apothecaries, selling various medicinal wares, were open to the public and from there, substances that were traditionally used for curative 
purposes were employed for their negative uses. At the same time, in the Middle East, Arabs developed a form of arsenic that is odorless and transparent, making the poison difficult to detect. This unhealthy "poison epidemic" was also prevalent in parts of Asia at this time, as well. In the modern world, intentional poisoning is less common than in the middle Ages; rather, the more common concern is the risk of accidental poisoning from everyday substances and products. Cyanide is a singularly charged anion consisting of one carbon atom and one nitrogen atom joined with a triple bond, $\mathrm{CN}$-. The most toxic form of cyanide is free cyanide, which includes the cyanide anion itself and hydrogen cyanide, HCN, either in a gaseous or aqueous state. HCN is highly soluble in water. HCN gas and liquid are colorless and have the odor of bitter almonds. Plant materials containing $\geq 200$ ppm of cyanogenic glycosides are dangerous. Hydrogen cyanide was first isolated from Prussian blue dye in 1786 and cyanide first extracted from almonds around 1800. It can exist as a gas, hydrogen cyanide, a salt, potassium cyanide. Natural substances in some foods such as lima beans, almonds can release cyanide. Cyanide is also found in manufacturing and industrial sources such as insecticides, photographic solutions, and jewelry cleaner. It has been used as a poison in mass homicides and suicides. During World War II, the Nazis used cyanide as an agent of genocide in gas chambers ${ }^{3 ; 4}$ Cyanide's main effect is that it inhibits oxidative phosphorylation, a process where oxygen is utilized for the production of essential cellular energy sources in the form of ATP. It does so by binding to the enzyme cytochrome C oxidase and blocks the mitochondrial transport chain. After that, cellular hypoxia and the depletion of ATP occur, leading to metabolic acidosis. The utilization of oxygen by the tissue occurs and is followed by the impairment of vital functions ${ }^{5}$ Signs generally occur within 15-20 min to a few hours after animals consume toxic forage, and survival after onset of clinical signs is rarely $>2 \mathrm{hr}$. Excitement can be displayed initially, accompanied by rapid respiration rate. Dyspnea follows shortly, with tachycardia. The classic "bitter almond" breath smell may be present. Animals may stagger and struggle before collapse. In other cases, sudden unexpected death may ensue. Mucous membranes are bright red but may become cyanotic terminally. Venous blood is classically described as "cherry red" because of the presence of high venous blood $\mathrm{pO}_{2}$; however, this color rapidly changes after death. Serum ammonia and neutral and aromatic amino acids are typically increased. Cardiac arrhythmias are common due to myocardial histotoxic hypoxia. Death occurs during severe asphyxial convulsions. The heart may continue to beat for several minutes after struggling, and breathing stops. Normally expected cyanide concentrations in blood of most animal species are usually $<0.5 \mathrm{mcg} / \mathrm{ml}$ Cyanide concentrations in muscle are similar to those in blood, but concentrations in liver are generally lower than those in blood. Differential diagnoses include poisonings by nitrate or nitrite, urea, organophosphate, carbamate, chlorinated hydrocarbon pesticides, and toxic gases (carbon monoxide and hydrogen sulfide), as well as infectious or noninfectious diseases and other toxidromes that cause sudden death. 6

Elaeis guineensis is a species of palm commonly called African oil palm. It is the principal source of red palm oil or macaw-fat and palm kernel oil. It is native to west and southwest Africa, specifically the area between Angola and the Gambia. The species name guineensis refers to the name for the area, and not necessarily the modern country which now bears that name. The pericarp consists of the exocarp (the outer layer also referred to as the skin), the mesocarp (the layer containing the red palm oil), and the endocarp (consisting of a hard shell enclosing the kernel or endosperm, which contains the kernel oil) (Palm oil is extracted from fleshy mesocarp of the fruit either by milling mechanically or by the traditional manual method, ${ }^{7}$ which contains 45 - 55\% oil, but varies from light yellow to orangered in color, and melts at $25^{\circ} \mathrm{C}$. The oil colour is determined by its carotenoids. The major carotenoids found in palm oil are the beta-carotene1. Palm kernel oil is obtained from the kernels enclosed in the endocarp. Palm oil contains saturated palmitic acid, oleic and linoleic acid, giving it a higher unsaturated acid content than palm kernel or coconut oils. Palm oil also has some minor constituents including phospholipids. Folk remedies of oil palm also include treatment for cancer and use as liniment ${ }^{\mathbf{8}}$ It has shown to prevent premature aging, protection of the liver, and reduction of risk of cancer 9;10; 11 Fresh palm oil is the most common antidote for ingested poisons in South-South Nigeria. It is also used as cough remedy. Palm oil has wound healing properties hence it is implored in the treatment of wounds and cuts as well as in treatment of burns. In Igbo land, palm oil and raw egg white (albumin) is formed into a homogenous mixture and used on burnt skin to promote healing and enhance the regeneration of tissue. Eight leaves of Vernonia amygdalis fried in little quantity of pure palm oil is used in treatment of burns on the skin. Skin rashes, measles, boils and itches are some of the skin infections that are treated with red palm oil. Studies carried out at the Michael Okpara University of Agriculture, Umudike, Abia State, Nigeria 12 using five microorganisms which includes; Staphylococcus aureus, Escherichia coli, Pseudomonas areuginosa, Candida albicans, and Aspergillus niger which are causative agents of some infections on the skin can be treated with palm oil and palm kernel oil. In the past, some health researchers thought palm oil could increase the risk of heart disease because of its high content of saturated fatty acids, but today further research by scientist has proved that palm oil contains no cholesterol and that it has lots of the short-chain fatty acids which are helpful to the humans. Palm oil provides a rich source of beta-carotene and vitamin E, namely tocopherols and tocotrienols which are recognized nutritional anti-oxidants that act as scavengers of the oxygen atom or free radicals. Research has shown that consumption of red palm oil enhances vitamin A levels in humans, and it is beneficial in preventing vitamin A deficiency ${ }^{13}$ Vitamin A deficiency may lead to blindness, skin disease and weakened immune function. The vitamin A content in red palm oil plays important roles in growth, development and in visual process. Studies have indicated that the potential mechanism of action for the improvement in glucose metabolism with palm oil involves inhibition of the enzyme dipeptidyl peptidase-4, 14 the effect of which is to 1protect gastric inhibitory polypeptide, which itself stimulates insulin secretion, and in the other hand suppresses glucagon secretion and slows gastric emptying. E. guineensis oil is rich in catechins and polyphenols. In a human clinical trial, the patients who were given supplements 'palm tocotrienol complex' for two months showed significant reduction in aortic systolic blood pressure. Tocotrienol-rich Fraction (TRF) of palm oil exhibited cardio-protective ability in the experimental animals $\mathbf{1 5}$ Palm oil has anti-clotting effect and it helps in prevention of thrombus in the blood vessels. A human study showed that tocotrienol (from palm oil) supplementation can reduce stenosis of patients with carotid atherosclerosis.16 Other reports showed that palm oil diets increases the production of prostacyclin or thromboxane.17 Thus scientific evidence indicates that the palm oil diet is anti-thrombotic. Studies in animals confirmed that palm oil prevents the formation of plaques in the arteries 18 The antibacterial activity of this plant extract against different microorganisms and anti-oxidant activity have been reported 19 
Moreover, Chong together with Sasidharan and some others 20 described the potential of $E$. guineensis leaf methanol extract as an infected wound healing agents. Studies have shown that tocotrienols fractions of palm oil were able to induce an inhibitory action on the human breast cancer cells, whereas the alpha-tocopherols were not able ${ }^{21}$ Palm oil is composed of fatty acids, esterified with glycerol. Palm oil has an especially high concentration of saturated fat, specifically, of the 16-carbon saturated fatty acid palmitic acid, to which it gives its name. Monounsaturated oleic acid is also a major constituent of palm oil. Unrefined palm oil is a large natural source of tocotrienol 22 part of the vitamin E family.

\section{MATERIALS AND METHODS}

\section{Collection and preparation of plant materials}

A freshly harvested palm fruit was collected from Owerri in Imo state at The sample parts were identified by a taxonomist Mr. Ozioko, in the Department of Botany Nnamdi Azikiwe University Awka. After collection of the palm fruit, it was washed to remove impurities and boiled in $5 \mathrm{~L}$ of water to enhance the softening of the mesocarp. The fruits were sieved out from the water and were then pounded. The nuts were removed i.e. removal of the palm kernel. The fiber obtained from the pounded fruit was placed in a clean sieve/sac, and the oil was pressed out. This process was carried out while the fiber is hot. The crude extract obtained was boiled and final separation of the pure oil took place.

\section{Animals}

A total of 30 adult rats weighing between (81-100) $g$ of both sexes were obtained from Animal House of the Department of Pharmacology, Madonna University, Elele Campus, Rivers State. They were allowed to acclimatize for a period of 2 weeks as they had free access to food and water and were maintained under the standard conditions while in the house.

\section{Macroscopic examination}

The macroscopic examination was carried out. This includes organoleptic evaluation (taste, texture and smell).

\section{Determination of Moisture Content}

The moisture content was determined by finding the difference between the weight of the sample before drying and the weight of the sample after drying.

\section{Phytohemical Analysis}

Phytochemical screening was carried out to detect the presence for Flavonoids, Phenols, Tannins, Saponins, Alkaloids, Steroids, Terpenoids following standard methods

\section{Physicochemical analysis}

The physicochemical analyses were determined following the standard methods

\section{Acid Value}

To a mixture of $20 \mathrm{ml}$ ethanol and $20 \mathrm{ml}$ diethyl ether in a $250 \mathrm{ml}$ Erlenmeyer flask was added approximately $1 \mathrm{~g}$ Elaeis guineensis oil and shaken for about 20 seconds, 5 drops of phenolphthalein was added as an indicator, the mixture was titrated against the standardized $0.1 \mathrm{M}$ potassium hydroxide $(\mathrm{KOH})$ solution until a pink colour, which persisted for at least 15 seconds was observed. Burette reading $\mathrm{x}$ factor of alkali/ weight of oil.

\section{Saponification Value}

A $2 \mathrm{~g}$ of the sample was weighed and transferred into the distillation flask, fitted with a reflux condenser, then, $20 \mathrm{ml}$ of
$0.5 \mathrm{M}$ of potassium hydroxide $(\mathrm{KOH})$ was added. The flask was heated in boiling water under reflux for 1 hour and then cooled by placing in ice water. The mixture was titrated with $0.5 \mathrm{M}$ hydrochloride (HCL). A blank titration was also carried out.

Saponification value $=\mathrm{F} \times(\mathrm{b}-\mathrm{a}) \times 28.05 /$ weight of oil

$\mathrm{F}=$ Factor of $0.5 \mathrm{M} \mathrm{HCL}$

$\mathrm{b}=$ Volume of $0.5 \mathrm{M} \mathrm{KOH}$

$\mathrm{a}=$ volume of $0.5 \mathrm{M} \mathrm{HCL}$

\section{Ester Value}

Ester value $=$ saponification value - acid value

\section{Free Fatty Acid}

A $2.0 \mathrm{~g}$ of the extract (Elaeis guineensis oil) was transferred into $250 \mathrm{ml}$ Erlenmeyer flask followed by the addition of 50 $\mathrm{ml}$ of $\mathrm{n}$-hexane and $1 \mathrm{ml}$ of phenolphthalein indicator. The flask was shaked vigorous and titrated against $0.04 \mathrm{M} \mathrm{NaOH}$. The shaking continued until the observation of a slight pink color which was steady for about 15 seconds which signified the end point. The expression for free fatty acid (FFA) is as follows:

$$
\% \mathrm{FFA}=(\mathrm{V} \times \mathrm{M} \times 282 / \mathrm{W}) \times 100
$$

Where, $\%$ FFA = Percentage free fatty acid (oleic acid)

$\mathrm{V}=$ Average volume of $\mathrm{NaOH}$ used $(\mathrm{ml})$,

$\mathrm{M}=$ Molarity of $\mathrm{NaOH}$

$282 \mathrm{~g} / \mathrm{mol}=$ Molecular weight of oleic acid

$\mathrm{W}=$ Weight of oil

\section{Peroxide Value}

A $2.0 \mathrm{~g}$ of the Elaeis guineensis oil was weighed and dissolved in a mixture of glacial acetic acid and chloroform, at ratio (3:2), then, a $0.5 \mathrm{ml}$ saturated potassium iodide solution was added to the mixture in the flask and covered. The mixture was shaken for a minute then a $30 \mathrm{ml}$ of distilled water was added and titrated against $0.1 \mathrm{M}$ sodium thiosulphate solution $\left(\mathrm{Na}_{2} \mathrm{~S}_{2} \mathrm{O}_{3}\right)$ shaking vigorous, using starch mucilage as indicator. A sudden disappearance of the blue color signifies the end point. Blank determination was also carried out.

\section{Hydroxyl Value}

A 2.0 grams of the Elaeis guineensis oil was transferred into distillation flask fiited with a reflux condenser and a $1 \mathrm{ml}$ of acetic anhydride was added. The flask was boiled under reflux for 5 minutes and then was cooled by placing in iced water. The mixture was titrated with $0.5 \mathrm{M}$ ethanolic potassium hydroxide. Phenolphthalein was used as an indicator. A blank determination was also carried out

\section{Iodine Value}

A $0.4 \mathrm{~g}$ of the extract was weighed into conical flask and then dissolved by the addition of $20 \mathrm{ml}$ of carbon tetrachloride. After which, a $25 \mathrm{ml}$ of wij's reagent was added with the help of a safety pipette in a flame chamber. A stopper was inserted and the mixture was swirled vigorously before it was then placed in a dark room for 2.5 hours. At the end of this period, a $20 \mathrm{ml}$ of potassium iodide and a $125 \mathrm{ml}$ of water was added with the use of a measuring cylinder. The resulting solution was then titrated with $0.1 \mathrm{M}$ sodium thiosulphate solution $\left(\mathrm{Na}_{2} \mathrm{~S}_{2} \mathrm{O}_{3}\right)$ until the initial yellow color almost disappeared. Few drops of $1 \%$ starch indicator was then added with few drops of thiosulphate added 
meticulously as the titration continued shaking vigorous until the blue coloration disappears.

\section{Pharmacological Evaluation}

\section{Acute Toxicity}

The acute toxicity of Elaeis guineensis was carried out using the $\mathbf{2 3}$ The test was carried out in two phases. A total of 13 rats were employed. In phase one, a total of 9 rats were used, which were then grouped into 3 groups of 3 rats. Group 1, 2 and 3 received 10, 100 and $1000 \mathrm{mg} / \mathrm{kg}$ of the extracted oil orally respectively. The animals in the three groups were monitored for at interval of three hours until a period of 24 hours for mortality, the result observed was documented appropriately. In phase 2 , the animals were grouped into four groups containing one rat each. Group 1, 2, 3 and 4 received $2000,3000,4000$ and $5000 \mathrm{mg} / \mathrm{kg}$ of the oil respectively. The animals were also monitored for 24 hours for mortality, and the result was documented.

\section{Evaluation of the Antidotal effect of the Elaeis guineensis oil}

The antidotal activity of Elaeis guineensis oil was carried out using animal model. A total of 30 rats were used, they were grouped into 6 groups of 5 rats each, and each group of 5 rats had similar body weight. The animals received treatments as follows

Group 1(control 1): received a dose of $5 \mathrm{mg} / \mathrm{kg}$ of potassium cyanide only.

Group 2: received $3 \mathrm{ml}$ of Palm oil each at 0 minutes after administration of KCN at a dose of $5 \mathrm{mg} / \mathrm{kg}$.

Group 3: received $3 \mathrm{ml}$ of palm oil each at 4 minutes after administration of KCN at a dose of $5 \mathrm{mg} / \mathrm{kg}$.

Group 4: received $3 \mathrm{ml}$ of palm oil each at 8 minutes after administration of KCN at a dose of $5 \mathrm{mg} / \mathrm{kg}$.

Group 5: received $3 \mathrm{ml}$ of palm oil each at 12 minutes after administration of $\mathrm{KCN}$ at a dose $5 \mathrm{mg} / \mathrm{kg}$.

Group 6; (control 2): Each rat received $3 \mathrm{ml}$ of palm oil only.

All the administrations were through oral routes and the numbers of deaths were properly documented.

\section{Statistical Analysis}

Statical analysis of one way anova was carried out using a software Graph pad Prism5 version.

\section{RESULTS}

\section{Macroscopic Analysis}

Table1: Macroscopic Description of Elaeis guineensis oil

\begin{tabular}{ll}
\hline Characteristics & Observation \\
\hline Condition & Fresh \\
Texture & Smooth \\
Colour & Bright red \\
Taste & Characteristic taste \\
Appearance & Oily \\
Odour & Characteristic smell \\
\hline
\end{tabular}

\section{Toxicity Test}

There was no death recorded at the dose of $5000 \mathrm{mg} / \mathrm{kg}$ body weight of oil. This indicates that the oil is very safe.

\section{Physicochemical Properties}

Table 2: Physicochemical properties of Elaeis guineensis Oil

\begin{tabular}{ll}
\hline Parameter & Composition $(\% \mathbf{w} / \mathbf{w})$ \\
\hline Acid Value & 31.26 \\
Saponification Value & 194.8 \\
Ester Value & 163.54 \\
Free Fatty Acid & 3.65 \\
Peroxide Value & 18 \\
Iodine Value & 83 \\
Hydroxyl Group \% & 2.07 \\
\hline
\end{tabular}

\section{Qualitative Phytochemical Composition of Elaeis guineensis 0il}

Table 3: Phytochemical Screening of the Oil Sample

\begin{tabular}{ll}
\hline Phytochemical & Indication \\
\hline Flavonoids & Present \\
Phenols & Present \\
Tannins & Present \\
Saponins & Present \\
Alkaloids & Present \\
Steroids & Present \\
Terpenoids & Present \\
\hline
\end{tabular}

\section{Result from the Biological Activity for Antidotal Effect}

Table 4: The Biological Activity for the Antidotal Effect of the Extracted Oil

\begin{tabular}{|c|c|c|c|c|c|c|}
\hline Group & $\begin{array}{l}\text { Timebetween poisoning and } \\
\text { ant. Adm. }\end{array}$ & $\begin{array}{l}\text { Dose }(\mathrm{mg} / \mathrm{kg}) \text { of } \\
\text { cyanide }\end{array}$ & $\begin{array}{l}\text { Volume of oil } \\
\text { administered }(\mathrm{ml})\end{array}$ & extract & $\begin{array}{l}\text { Number } \\
\text { deaths }\end{array}$ & of \\
\hline 1 & ------- & 5 & ----- & & 5 & \\
\hline 2 & $0 \mathrm{~min}$ & 5 & 3 & & 0 & \\
\hline 3 & $4 \mathrm{~min}$ & 5 & 3 & & 0 & \\
\hline 4 & $8 \mathrm{~min}$ & 5 & 3 & & 3 & \\
\hline 5 & $12 \min$ & 5 & 3 & & 5 & \\
\hline 6 & ------- & ------ & 3 & & 0 & \\
\hline
\end{tabular}

Moisture content and volatile content $=0.2 \%$

\section{DISCUSSION AND CONCLUSION}

The phytochemical screening of Elaeis guineensis oil revealed the presence of several metabolites. In table 5, it is shown that Elaeis guineensis oil contains Tannins, Terpenoids, Alkaloids, phenols, Flavonoids. The presence of some of this metabolites may contribute to the effect of this plant as 
remedy for various diseases which includes, its antimicrobial effect, hepatoprotective effect, cardiovascular effect, treatments of wounds and even as antidotes for poison $\mathbf{2 4}$

Table 2 identifies the various physicochemical properties of Elaeis guineensis oil. From the values obtained for the Acid value, Saponification value, Ester value, peroxide value and Hydroxyl value, which is, 31.26, 137.3, 107.57, 18, and 83 respectively, the oil can be said to be of good quality, and safe for consumption. The moisture content of the oil indicates the presence of little or insignificant moisture content 25

Poisoning is common in humans and to treat the poisoning antidotes are used. In the treatment of cyanide poisoning, antidotes are classified as those needed immediately (WHO). The average fatal concentration for humans was estimated at $546 \mathrm{ppm}$ for $10 \mathrm{~min}$. This data point is based on the work of 26 who considered the resistance of man to HCN to be similar to that of the goat and monkey and four times that of the mouse. With these, the rats were grouped according to time interval ranging from 0-12 min. In Table 4, it is shown that the group 2, 3 and 6 had zero number of death, this were the groups given antidote at 0 and $4 \mathrm{~min}$ and the group not given poison at all. Groups 1 and 5 had the maximum number of deaths, which is the group not given antidote and the group given antidote at 12 minutes after poison administration.

The results obtained at the $4^{\text {th }}$ and $8^{\text {th }}$ min, shows the role of quick intervention in administration of Elaeis guineensis oil as an antidote in cyanide poisoning. Time factor is essential in this form of intervention from the result obtained, the best activity of Elaeis guineensis oil within the earliest possible time is about $4 \mathrm{~min}$ as indicated in Table 5 . At the $12^{\text {th }} \mathrm{min}$ the entire cyanide must have been absorbed into the blood stream, and the application of Elaeis guineensis oil at this stage is unable to revert the injuries caused by this poison on the organs.

\section{CONCLUSION}

Elaeis guineensis oil is a rich source of numerous metabolites good for the human health. From the results obtained, Elaeis guineensis can be said to be more effective as an antidote to cyanide poisoning before the poison being ingested is absorbed into the systemic circulation, i.e., into the blood stream. This mechanism can be attributed to the saponification activities, neutralizing action and presence of fatty acids which delays gastric absorption and promotes gastric emptying. According to WHO certain agents used in the treatment of poisoning can be classified under those needed immediately, within 2 hours and within 6 hours.

\section{REFERENCES}

1. Obahiagbon F.I "A Review: Aspects of the African Oil Palm (Elaeis guineesis Jacq.)". American Journal of Biochemistry and Molecular Biology: 2012; 1-14.

2. Merriam-Webster, https://www.merriamwebster.com/thesaurus/antidotes. Accessed 26 Feb. 2020

3. Culnan D. M., Craft-Coffman B, Bitz G.H, Capek K.D, Tu Y, Lineaweaver WC, Kuhlmann-Capek M J. (2018). Carbon Monoxide and Cyanide Poisoning in the Burned Pregnant Patient: An Indication for Hyperbaric Oxygen Therapy. Ann Plast Surg. 2012; 80(3 Suppl 2):S106-S112. [PMC free article] [PubMed]

4. Parker-Cote JL, Rizer J, Vakkalanka JP, Rege SV, Holstege CP. Challenges in the diagnosis of acute cyanide poisoning. Clin Toxicol (Phila). 2018; 56(7):609-617. [PubMed]

5. Huzar TF, George T, Cross JM. Carbon monoxide and cyanide toxicity: etiology, pathophysiology and treatment in inhalation injury. Expert Rev Respir Med. 2013; 7 (2):159-170. [PubMed]
6. Anseeuw K; Delvau N; Burillo-Putze G; De Iaco F; Geldner G; Holmström P; Lambert Y; Sabbe M "Cyanide poisoning by fire smoke inhalation: a European expert consensus".European Journal of Emergency Medicine 2013; 20(1):2-9. doi:10.1097/mej.0b013e328357170b. PMID 22828651.

7. Edem D 0. and Akpanabiatu M I. Effects of palm oil-containing diets on enzyme activities of rats. Pakistan Journal of Nutrion 2006; 5:301 - 305

8. Sasidharan S. and Vijayarathna S: Cytotoxicity of methanol extracts of Elaeis guineensis on MCF-7 and Vero cell lines. Asian pacific journal of tropical biomedicine 2012; 2:826-829

9. Edem DO, Palm Oil: Biochemical, physiological, nutritional, hematological, and toxicological aspects: A review. Plant. Foods Hum. Nutr. 2002; 57:319-341. doi: 10.1023/A:1021828132707. [PubMed] [CrossRef] [Google Scholar]

10. Ong AS., Goh SH. Palm Oil: A healthful and cost-effective dietary component. Food Nutr. Bull. 2002; 23:11-22. [PubMed] [Google Scholar]

11. Sen CK., Khanna S, Roy S: Tocotrienols in health and disease: The other half of the natural vitamin E family. Mol. Asp. Med. 2007; 28:692-728. doi: 10.1016/j.mam.2007.03.001. [PMC free article] [PubMed] [CrossRef] [Google Scholar]

12. Ekpa O D and Ebana RUB. Comparative Studies of Mmanyanga, Palm and Coconut Oils; Anti-microbial Effects of the Oils and their Metallic Soaps on Some Bacteria and Fungi. Global Journal Pure and Applied Science 1996; 2:155 - 163

13. Shunan Dong, Hui Xia, Feng Wang, and Guiju Sun: Effect of Red Palm Oil on Vitamin A Deficiency: A Meta-Analysis of Randomized Controlled Trails. 2017; 9(12):1281 Doi 10.3390/nu9121281

14. Abdullah Z.; Hussain K; Zhari I ; Rasadah MA ; Mazura P J. and Sahdan R. "Evaluation of extracts of leaf of three Ficus deltoidea varieties for antioxidant activities and secondary metabolites". Pharmacognosy Research 2009; (1):216 - 223

15. Abdullahhi, A. A.."Trends and challenged of traditional medicine in Africa". Afr. journal of traditional, complementary and alternative medicine 2011; 8(5S):115-23.

16. Das S.; Lekli I. ;Das M. ; Szabo,G and Varadi J.. Cardioprotection with palm oil tocotrienols: Comparison of different isomers. American Journal of Physiology Heart and Circulatory Physiology. 2008; 294:70 - 78.

17. Tomeo AC, Geller M, Watkins TR., Gapor A, Bierenbaum ML. Antioxidant effects of tocotrienols in patients with hyperlipidemia and carotid stenosis. Lipids. 1995; 30:11791183. doi: 10.1007/BF02536621. [PubMed] [CrossRef] [Google Scholar]

18. Mohamed A B, Imad K A, and Amon G. Effect of Palm Oil on Blood Pressure, Endothelial Function and Oxidative tress. Assian Pacific Journal of Clinical Nutrition 2005; 14(4):325-39.

19. G.Homstr: Dietary lipids and cardiovascular disease: Effects of palm oil Oleagineux 1988; 43:75-81

20. Sasidharan S ; Sharmini R; Vijayarathna S; Yoga Latha L; Vijenthi R and Amutha S.. Antioxidant and hepatoprotective activity of methanolic extracts of Elaeis guineensis Jacq leaf. Pharmacologyonline 2009; 384 - 90

21. Chong K H; Zuraini Z; Sasidharan S; Devi P V K; Latha L Y and Ramanathan $\mathrm{S}$ timicrobial of Elaeis guineensis leaf Pharmacologyonline 2008; 3:379-386

22. Nesaretnam K; Khor H T; Ganeson J; Chong K and Gapor A.. "The effect of vitamin E tocotrienols from palm oil on chemically-induced mammary carcinogenesis in female rats". Nutrition Research 1992; 12:879-892

23. Manorama and Rukmini,. Chemical analysis of the fatty acids composition of the red palm oil indicates that it has about $50 \%$ saturated. Nutritional evaluation of crude palm oil in rats:Am.J.Clin.Nutr. 1991; 53:1031S-1033S.

24. Lorke, D. A New Approach to practical Acute Toxicity Testing Arch. Toxicol1983; 54:275-287

25. Ekwenye U. N and Ijeomah C.A. Antimicrobial effects of palm kernel oil and palm oil KMITL Sci J2005; 5:502 - 505

26. Tan YA; Kunyom A; Siew WL; Yusof M; Chong CL. PORIM tech. Palm oil research institute of Malaysia 2000; 22

27. McNamara B.P: Estimates of the toxicity of hydrocyanid acid vapors in man. Edgewood Arsenal Technical Report EB-TR76023, Department of the Army, August, 1976. 